\title{
Comparison of Macular and RNFL Thickness in Anisometropic Amblyopia as Compared to Normal Fellow Eyes
}

\author{
Bharti NIGAM', Pragati GARG', Priyanka RAJ'
}

\begin{abstract}
Purpose: To compare the macular and peripapillary RNFL thicknesses of the amblyopic and normal eye in patients with anisometropic amblyopia. Methods: This is a hospital based cross-sectional study for which we studied 36 amblyopic subjects aged between 5 to 16 years in which the amblyopic eye was taken as the case and the unaffected eye was taken as control eye. The inclusion criteria included children having unilateral strabismic or anisometropic amblyopia who underwent macular and RNFL thickness assessment by SD-OCT. Results: Central Macular thickness as well as the thickness of the other macular segments was significantly greater in the affected eye $(p<0.001)$ as compared to the normal eye. The average RNFL thickness was also found to be increased in the affected eye but the difference was not statistically significant $(p=0.106)$, however it was statistically significant in quadrantic analysis $(p<0.05)$. The Central Macular thickness showed a negative correlation with the BCVA $(r=-$ $0.252)$, although it was not statistically significant $(p=0.139)$. Conclusion: A significant increase was found in the macular as well as RNFL thickness in the amblyopic eyes as compared to the normal fellow eye which support the hypothesis of decreased apoptosis of the ganglion cells postnatally.
\end{abstract}

Keywords: RNFL thickness, amblyopia, macular thickness, anisometropia, nerve fibre layer.

\section{INTRODUCTION}

Amblyopia is the most frequent cause of unilateral poor visual acuity (VA) in children, with an incidence of $0.20 \%$ to $6.2 \%$ in preschool and school-age children ${ }^{1}$. Amblyopia involves loss of Snellen and grating acuity, loss of contrast sensitivity and creation of distortions in the shape of a stimulus ${ }^{2}$. Amblyopia is thought to occur during the period of neuronal development of the retina and the cerebral cortex. Therefore, it frequently arises during the first 2-3 years of childhood. However, it

1 Department of Ophthalmology, Era's Lucknow Medical College and Hospital, Sarfarazganj, Uttar Pradesh, India may also occur in children up to 8-9 years and persists life-long.

Optical coherence tomography (OCT) is a non-invasive, noncontact technique that visualizes the retinal structure in vivo newer spectral domain machines may approach 3 micron resolution ${ }^{3}$, and can measure the thickness of both peripapillary retinal nerve fiber layer (RNFL) and macula retinal layer which can be used as a helpful tool in assessing retinal changes in amblyopia

During fetal development, there is a rapid decline in cell density in the retinal ganglion cell layer toward

\section{Corresponding author.}

Bharti NIGAM, Department of Ophthalmology, Era's Lucknow Medical College and Hospital, Sarfarazganj, Hardoi Road, Lucknow, Uttar Pradesh, India - 226003.

E-mail: drpriyankarajy@gmail.com 
the end of gestation. In humans, the total population of cells in the ganglion cell layer is highest (2.2-2.5 million cells) between approximately 18 and 30 weeks of gestation. After this, the cell population declines rapidly. If amblyopia affects the process of postnatal reduction of ganglion cells, RNFL thickness may be thicker than that in the normal eye ${ }^{4}$. Similarly, decreased foveal depression have been reported in amblyopic patients on ophthalmoscopic examination. Foveal depression and reflex are absent in these eyes and slight discoloration (Wine coloration) of the fovea is sometimes observed, however, these are not consistent findings in the amblyopic fundus 5 .

Thus, this study was taken up to compare the macular and peripapillary RNFL thicknesses of the amblyopic eye and the normal eye in patients with anisometropic amblyopia to find the potential initial neural site of the visual deficit in this condition.

\section{MATERIALS AND METHODS}

This is a hospital based cross-sectional study for which we enrolled 45 amblyopic subjects aged between 5 to 16 years in which the amblyopic eye was taken as the case and the unaffected eye was taken as control eye. The inclusion criteria included children having unilateral strabismic or anisometropic amblyopia with the informed and written consent of their legal guardian. We excluded children having any systemic disorder affecting eyes, nystagmus, corneal opacities, glaucoma, retinal disorders, any inflammatory condition of the eye, history of severe ocular trauma and the patients who refused to participate in the study. And finally we were left with 36 patients who underwent further evaluation.

All patients underwent a detailed eye examination including best corrected visual acuity (BCVA) determination using Snellen chart from $6 \mathrm{~m}$ distance, manifest refraction and cycloplegic refraction after pupillary dilation with $1 \%$ cyclopentolate hydrochloride and $1 \%$ tropicamide, alternative cover test, duction and version testing, intraocular pressure (IOP) measurement, slitlamp biomicroscopy and fundus examination. In this study, anisometropia was defined as a cycloplegic, spherical equivalent difference greater than 2.00 diopter (D) between fellow eyes.

Further the patients underwent macular and RNFL thickness assessment by spectral domain OCT using Carl Zeiss Cirrus HD OCT. All scans were of high quality (signal strength $\geq 7$ ), lacked centration errors, and had minimal segmentation errors. We excluded scans of signal strength $<7$ and those with centration errors. The proprietary Cirrus segmentation algorithm was used to produce retinal thickness maps, which were then averaged over nine retinal subfields within a 6-mm diameter circle centered at the true foveal location, as defined by the Age-Related Eye Disease Study. Macular thickness measurements were obtained in macular cube $512 \times 128$ combination scan mode. The $6 \times 6$ $\mathrm{mm}$ circle corresponds to the Early Treatment Diabetic Retinopathy Study subfield, which is segmented by a concentric circle into central, inner, and outer circles $(1,3$, and $6 \mathrm{~mm})$. The inner and outer circles were both subdivided into four quadrants (superior, inferior, nasal, and temporal) to give nine areas in total. The thickness of each area was measured. The optic disk cube $200 \mathrm{x}$ 200 scan mode was used to image the optic disk and RNFL over a 6 x 6 mm optic nerve head using $200 \mathrm{x}$ 200 axial measurements.

The RNFL thickness of the four quadrants (superior, inferior, nasal, and temporal) was then measured.

Data was analyzed using IBM-SPSS Version 21.0 software. Data has been represented as numbers and percentages and mean \pm SD. Paired ' $t$ '-test was used for comparison. A 'p'value less than 0.05 indicates a significant difference

\section{OBSERVATION AND RESULTS}

This is a hospital based cross-sectional study carried out at a tertiary centre of north India for which 36 subjects with unilateral amblyopia were enrolled.

A total of 36 patients (18 males and 18 females) aged between 5 to 16 years (mean age $11.58 \pm 4.96$ years) were enrolled in the study. In $69.4 \%$ cases right eye was affected as opposed to only $30.6 \%$ subjects in whom left eye was affected. Mean best corrected visual acuity of affected eye was $1.21 \pm 0.32 \operatorname{LogMAR}$ as compared to $0.56 \pm 0.21 \operatorname{LogMAR}$ for the unaffected eye (Table 1).

Total mean of total RNFL thickness of affected side (106.81) was greater than that of unaffected side (98.58) but difference was not found to be significant $(p=0.106)$. An increase in the RNFL thickness was observed in the affected eye for superior (136.19), temporal (61.97) and inferior (100.89) quadrants as compared to the unaffected side, where the thickness of the respective quadrants were found to be 96.31, 85.03 and 85.03 respectively but the difference was statistically significant for superior and inferior quadrants 
Table 1. Profile of patients enrolled in the study

\begin{tabular}{|c|c|c|}
\hline SN & Characteristic & Statistic \\
\hline 1. & Mean Age $\pm S D$ (Range) in years & $11.58 \pm 4.96(8-15)$ \\
\hline 2. & \begin{tabular}{|l|} 
Sex \\
$\quad$ Male \\
Female \\
\end{tabular} & $\begin{array}{l}18(50.0 \%) \\
18(50.0 \%) \\
\end{array}$ \\
\hline 3. & $\begin{array}{c}\text { Affected eye } \\
\text { Left } \\
\text { Right }\end{array}$ & $\begin{array}{l}11 \text { (30.6\%) } \\
25(69.4 \%)\end{array}$ \\
\hline 4. & $\begin{array}{c}\text { Mean } \pm \text { BCVA (LogMAR) } \\
\text { Affected side } \\
\text { Unaffected side }\end{array}$ & $\begin{array}{l}1.21 \pm 0.32 \\
0.56 \pm 0.21\end{array}$ \\
\hline
\end{tabular}

$(\mathrm{p}<0.001)$. In nasal segment average RNFL of affected side was significantly lower (54.22) as compared to that of unaffected side (68.00; $\mathrm{p}=0.001$ ) (Table 2).

Macular thickness also showed significant differences between affected and unaffected side. The thickness of central subfield area (267.89), inner superior (341.58), inner inferior (343.31), inner nasal (340.75), outer superior (316.94), outer temporal (292.25), outer inferior (292.36) and outer nasal (316.97) segment of the affected eye were higher than those of the unaffected eye $(241.86,333.81,319.03,327.97,321.94,307.19$, $285.42,287.81$ in the respective segments) which was statistically significant $(\mathrm{p}<0.001)$ in all but inner superior segment $(\mathrm{p}=0.035)$ (Table 3$)$.

In the study, comparison of BCVA, with the Macular and peripapillary RNFL thickness between normal and abnormal eye in children with unilateral amblyopia was done. It was observed that while assessing the relationship between the RNFL thickness and $\mathrm{BCVA}$, there was a positive correlation in the average $(\mathrm{r}=0.262, \mathrm{P}=0.123)$, superior $(\mathrm{r}=0.192, \mathrm{p}=0.262)$, inferior $(\mathrm{r}=0.169, \mathrm{p}=0.325)$ and nasal quadrants $(\mathrm{r}=0.118$, $\mathrm{p}=0.492$ ) except temporal, which showed a negative correlation $(r=-0.065, p=0.707)$ although it was not statistically significant. Since the worse vision is indicated by a higher LogMAR value, hence, the Pearson correlation came out to be positive when compared with the increased RNFL thickness (Table 4).

In the correlative study of BCVA(LogMAR) with macular thickness, the Central Macular thickness showed a negative correlation with the BCVA ( $r=-$ 0.252 ), although it was not statistically significant $(\mathrm{p}=0.139)$. There was a positive correlation in inner superior $(r=0.066 ; p=0.701)$, inner temporal $(r=0.708$ : $\mathrm{p}=0.000)$, inner inferior $(\mathrm{r}=0.145 ; \mathrm{p}=0.400)$, outer superior $(r=0.159 ; \mathrm{p}=0.353)$ and outer inferior $(\mathrm{r}=0.099$; $\mathrm{p}=0.566)$ quadrants, while inner nasal ( $\mathrm{r}=-0.029$; $\mathrm{p}=0.869)$, outer temporal $(\mathrm{r}=-0.173 ; \mathrm{p}=0.313)$ and outer nasal $(r=-0.156 ; p=0.364)$ quadrant. showed negatve correlation The statistical significance was reached the inner temporal quadrant $(p=0.000)$, while the correlation with the rest of the quadrants was statistically insignificant (Table 5).

\section{DISCUSSION}

In the present hospital based observational study conducted at a tertiary care hospital of north India, we have attempted to study the effect of amblyopia on macular and RNFL thickness in subjects aged between 5 to 16 years.

We studied 36 patients with unilateral amblyopia with equal number of males and females (18 males and 18 females) which is in contrast with other studies which had greater number of male subjects as compared to the female subjects ${ }^{5-11}$. More number of subjects had right side affected as compared to the left eye [25 (69.4\%) and 11 (30.6\%) respectively]. No other study, to the best of our knowledge, has reported such comparison. Although we could explain this discrepancy but it may be the result of embryonal developmental behaviour

On comparing the RNFL thickness between the amblyopic and unaffected eye we found significant difference in the values of both. The RNFL thickness was greater in the amblyopic eye as compared to the

Table 2. Comparison of RNFL Thickness $(\mu \mathrm{m})$ between affected and unaffected eye

\begin{tabular}{|c|c|c|c|c|c|c|c|}
\hline \multirow{2}{*}{ SN } & \multirow{2}{*}{ Segment } & \multicolumn{2}{|c|}{ Affected side $(n=36)$} & \multicolumn{2}{|c|}{ Unaffected side $(n=36)$} & \multicolumn{2}{|c|}{$\begin{array}{l}\text { Significance of difference } \\
\text { (Paired 't'-test) }\end{array}$} \\
\hline & & Mean & SD & Mean & SD & 't' & 'p' \\
\hline 1. & Total peripapillary RNFL thickness & 106.81 & 16.88 & 98.58 & 18.30 & 1.662 & 0.106 \\
\hline 2. & Superior & 136.19 & 12.86 & 96.31 & 15.81 & 9.489 & $<0.001$ \\
\hline 3. & Temporal & 61.97 & 7.45 & 58.58 & 7.52 & 2.207 & 0.034 \\
\hline 4. & Inferior & 100.89 & 8.81 & 85.03 & 5.96 & 8.434 & $<0.001$ \\
\hline 5. & Nasal & 54.22 & 16.84 & 68.00 & 14.39 & -3.589 & 0.001 \\
\hline
\end{tabular}


Bharti NIGAM et al.

Table 3. Comparison of macular Thickness $(\mu \mathrm{m})$ between affected and unaffected eye

\begin{tabular}{|c|c|c|c|c|c|c|}
\hline \multirow[t]{2}{*}{ Segment } & \multicolumn{2}{|c|}{ Affected side $(n=36)$} & \multicolumn{2}{|c|}{ Unaffected side $(n=36)$} & \multirow{2}{*}{$\begin{array}{c}\begin{array}{c}\text { Significance } \\
\text { of difference } \\
\text { (Paired 't'-test) }\end{array} \\
\text { 't' }\end{array}$} & \multirow[b]{2}{*}{ 'p' } \\
\hline & Mean & SD & Mean & SD & & \\
\hline CST* & 267.89 & 33.56 & 241.86 & 28.57 & 7.448 & $<0.001$ \\
\hline Average Cube & 297.56 & 12.44 & 278.92 & 13.10 & 8.347 & $<0.001$ \\
\hline Volume Cube & 9.77 & 0.21 & 9.80 & 0.24 & -0.952 & 0.348 \\
\hline Inner superior & 341.58 & 21.12 & 333.81 & 10.86 & 2.187 & 0.035 \\
\hline Inner temporal & 328.08 & 5.27 & 319.03 & 7.55 & 7.035 & $<0.001$ \\
\hline Inner inferior & 343.31 & 6.11 & 327.97 & 10.77 & 7.644 & $<0.001$ \\
\hline Inner nasal & 340.75 & 11.07 & 321.94 & 9.72 & 7.158 & $<0.001$ \\
\hline Outer superior & 316.94 & 9.91 & 307.19 & 8.18 & 4.828 & $<0.001$ \\
\hline Outer temporal & 292.25 & 6.80 & 285.42 & 5.70 & 5.751 & $<0.001$ \\
\hline Outer inferior & 292.36 & 4.45 & 287.81 & 4.19 & 5.886 & $<0.001$ \\
\hline Outer nasal & 316.97 & 3.31 & 310.81 & 3.76 & 7.098 & $<0.001$ \\
\hline
\end{tabular}

unaffected control eye and it was found to be significant in superior, inferior and nasal quadrants. This was in concordance to the results reported by Alotaibi et al. ${ }^{8}$ who found that that the average RNFL thickness in the amblyopic eyes were significantly greater than that of the normal eye [112.16 (12.67) and 106 (8.91), respectively: $p=<0.001]$. This finding was supported by the reports of Chatterjee et al. ${ }^{11}$ and Yen et al. ${ }^{7}$, though the difference did not reach any statistical significance in their studies.

The macular thickness in our study was also found to be greater in the amblyopic eye as compared to the normal control eye. The Central macular thickness was significantly higher in the amblyopic eye $(p<0.001)$ as well as in all the quadrants $(\mathrm{p}<0.001)$ except in the inner superior quadrant where the difference did not reach statistical significance. Agrawal et al. ${ }^{12}$ also reported a similar increment in the macular thickness in the amblyopic eye with Mean macular thickness in the amblyopic eyes being $277.5 \mu \pm 15.3$ and in the fellow normal eyes being $272.4 \mu \pm 13.1(\mathrm{P}<0.05)$. Although Rajavi ${ }^{5}$ et al. used external age matched controls to compare the macular thickness between the amblyopic and normal eyes, he also found a significant difference in central macular thickness between eyes with moderate to severe amblyopia and the external controls ( $\mathrm{P}$ $=0.037)$. In a similar comparison drawn by Hyuhn et al. ${ }^{10}$ amblyopic eyes had slightly greater foveal minimum thickness than the normal fellow eye (by $5.0 \_\mathrm{m}$; $95 \%$ confidence interval 0.1-9.9). Amblyopic eyes were found to have a slightly thicker central macula $(1 \mathrm{~mm}$ diameter region) in both comparisons, although these differences were not statistically significant. He also compared the RNFL thickness among the two, but did not find any significant difference between amblyopic and normal fellow eyes or normal eyes of non-amblyopic children. Chatterjee et al. ${ }^{11}$ studied the difference in the macular thickness of the anisometropic and strabismic amblyopic eyes in comparison to the normal fellow eye and found that the macular thickness of the amblyopic eye was greater than that in the normal eye in the anisometropic amblyopia group, [247.8947+/34.3926 in amblyopic eye versus 222.2386+/-31.1919 in the normal eye, $p=0.00106$ ] but failed to reach a statistical significance in the mean macular thickness (in microns) $233.75+/-31.5224$ in strabismic amblyopic eye versus $223.00+/-31.4266$ in normal eye a $(\mathrm{p}=$ $0.4118)$.

Table 4: Relationship between RNFL thickness the amblyopic eye with the BCVA

\begin{tabular}{|l|c|c|c|c|c|}
\hline \multirow{2}{*}{} & \multirow{2}{*}{ Average } & \multicolumn{4}{|c|}{ RNFL QUADRAN } \\
\cline { 3 - 6 } & & Superior & Temporal & \multirow{2}{*}{ Inferior } & \multirow{2}{*}{ Nasal } \\
\cline { 3 - 6 } & & 0.262 & -0.065 & 0.169 & 0.118 \\
\hline Pearson correlation $(r)$ & 0.123 & 0.262 & 0.707 & 0.325 & 0.492 \\
\hline
\end{tabular}


Comparison of Macular and RNFL Thickness in Anisometropic Amblyopia as Compared to Normal Fellow Eyes

Table 5: Relationship between macular thickness in the amblyopic eye with the BCVA

\begin{tabular}{|c|c|c|c|c|c|c|c|c|c|c|c|}
\hline & CST & $\begin{array}{l}\text { AVG } \\
\text { Cube }\end{array}$ & $\begin{array}{c}\text { Volume } \\
\text { Cube }\end{array}$ & $\begin{array}{c}\text { Inner } \\
\text { Superior }\end{array}$ & $\begin{array}{c}\text { Inner } \\
\text { Temporal }\end{array}$ & $\begin{array}{c}\text { Inner } \\
\text { Inferior }\end{array}$ & $\begin{array}{l}\text { Inner } \\
\text { Nasal }\end{array}$ & $\begin{array}{c}\text { Outer } \\
\text { Superior }\end{array}$ & $\begin{array}{c}\text { Outer } \\
\text { Temporal }\end{array}$ & $\begin{array}{c}\text { Outer } \\
\text { Inferior }\end{array}$ & $\begin{array}{l}\text { Outer } \\
\text { Nasal }\end{array}$ \\
\hline \begin{tabular}{|l|} 
Pearson \\
correlation $(r)$
\end{tabular} & 0.252 & 0.319 & 0.130 & 0.066 & 0.708 & 0.145 & -0.029 & 0.159 & -0.173 & 0.099 & -0.156 \\
\hline Significance $(p)$ & 0.139 & 0.058 & 0.448 & 0.701 & 0.000 & 0.400 & 0.869 & 0.353 & 0.313 & 0.566 & 0.364 \\
\hline
\end{tabular}

Wang et al. ${ }^{12}$ studied 14 subjects with hyperopic anisometropic amblyopia and reported no significant differences in peripapillary retinal nerve fiber layer, central macular thickness, and macular volume between amblyopic eyes and fellow eyes of the participants. Similarly, Dickmann et al. ${ }^{13}$ reported no significant difference between retinal nerve fiber layer thickness, macular thickness, and foveal volume in amblyopic versus fellow eyes in patients with unilateral amblyopia. However, Pang et al. ${ }^{14}$ reported that amblyopic children with unilateral high myopia tend to have a thicker fovea and thinner inner and outer macular ring in the amblyopic eye as compared to their normal fellow eye.

We also found an inverse correlation between the RNFL and Macular thickness and Best corrected visual acuity in the amblyopic eye. There was a positive correlation between the BCVA (LogMar) and RNFL thickness, average as well as in all the quadrants except in the temporal quadrant. Similar positive correlation was found between the BCVA (LogMAR) and the macular thickness, except in the inner nasal, outer temporal and outer nasal quadrants. The higher the LogMAR value worse is the visual acuity, hence there was a positive correlation with the RNFL and macular thickness. To the best of our knowledge, no other study has derived the correlation between the RNFL and Macular thickness with the visual acuity.

Yen et al. ${ }^{7}$ hypothesised that amblyopes have thicker retina and that the amblyopic process have effects at multiple levels in the visual pathway. Experiments have proved that retinal ganglion cells suffer changes with light deprivation from birth. These changes may include some or all of these- cell loss or apoptosis ${ }^{11}$, mean nucleolar volume diminution in ganglion cell layers, and inner plexiform layer thinning in rats and cats. Changes also include reduction in optic nerve head area in mice ${ }^{6}$. Arden ${ }^{15}$ showed that pattern ERG was reduced in various types of amblyopia in human. The amblyopic process may have an effect on various levels of the visual pathway.

Histopathologic changes in the lateral geniculate nucleus and visual cortex have been reported. Histologic study of the lateral geniculate nucleus of monkeys with strabismic, anisometropic, and visual deprivation amblyopia reveals marked shrinkage of cells that receive input from the amblyopic eye. ${ }^{5,8,9}$ There are similar findings in the lateral geniculate nucleus in human anisometropic amblyopia and strabismic amblyopia ${ }^{11}$. But we also think that at least in humans amblyopia may be associated with changes that affect retinal function at the level of production of Pattern ERG deficit, which is assumed to be preganglionic, however other studies 16 have refuted this claim, especially those in which fixation and focus were pre adjusted.

\section{CONCLUSION}

In our study we found a significant increase in the macular as well as RNFL thickness in the amblyopic eyes as compared to the normal fellow eye which support the hypothesis of decreased apoptosis of the ganglion cells postnatally. This baseline evaluation can be used to monitor the occlusion therapy thereafter and hence, changes in the macular and RNFL thickness can be evaluated after a successful occlusion therapy.

Compliance with ethics requirements: The authors declare no conflict of interest regarding this article. The authors declare that all the procedures and experiments of this study respect the ethical standards in the Helsinki Declaration of 1975, as revised in 2008(5), as well as the national law. Informed consent was obtained from all the patients included in the study. 


\section{References}

1. Chia A, Dirani M, Chan YH, Gazzard G, Au Eong KG, Selvaraj P, Ling Y, Quah BL, Young TL, Mitchell P, Varma R, Wong TY, Saw SM. Prevalence of amblyopia and strabismus in young singaporean chinese children. Invest Ophthalmol Vis Sci. 2010 Jul;51(7):3411-7.

2. McKee SP, Levi DM, Movshon JA. The pattern of visual deficits in amblyopia. J Vis. 2003;3(5):380-405.

3. Wojtkowski M, Bajraszewski T, Gorczyńska I, Targowski P, Kowalczyk A, Wasilewski W, Radzewicz C. Ophthalmic imaging by spectral optical coherence tomography. Am J Ophthalmol. 2004 Sep;138(3):412-9.

4. Yen MY, Cheng CY, Wang AG. Retinal nerve fiber layer thickness in unilateral amblyopia. Invest Ophthalmol Vis Sci. 2004;45(7): 2224-2230.

5. Rajavi Z, Moghadasifar H, Feizi M, Haftabadi N, Hadavand R, Yaseri M, Sheibani K, Norouzi G. Macular thickness and amblyopia. J Ophthalmic Vis Res. 2014 Oct-Dec;9(4):478-83.

6. Agrawal S, Singh V, Singhal V. Cross-sectional study of macular thickness variations in unilateral amblyopia. J Clin Ophthalmol Res 2014;2:15-7

7. Yen MY, Cheng CY, Wang AG. Retinal nerve fiber layer thickness in unilateral amblyopia. Invest Ophthalmol Vis Sci. 2004 Jul;45(7):2224-30

8. Alotaibi AG, Al Enazi B. Unilateral amblyopia: Optical coherence tomography findings. Saudi J Ophthalmol. 2011 Oct;25(4):4059.

9. Repka MX, Goldenberg-Cohen N, Edwards AR. Retinal nerve fiber layer thickness in amblyopic eyes. Am J Ophthalmol. 2006 Aug;142(2):247-51.
10. Huynh SC, Samarawickrama C, Wang XY, Rochtchina E, Wong TY, Gole GA, Rose KA, Mitchell P. Macular and nerve fiber layer thickness in amblyopia: the Sydney Childhood Eye Study. Ophthalmology. 2009 Sep;116(9):1604-9.

11. Chatterjee A, Bandyopadhyay SK. Macular thickness and peripapillary nerve fiber layer thickness in children with anisometropic and strabismic amblyopia- A comparative study. Journal of Medical Science And clinical Research. 2019;7(6).

12. Wang B, Taranath D. A comparison between the amblyopic eye and normal fellow eye ocular architecture in children with hyperopic anisometropic amblyopia. Journal of American Association for Pediatric Ophthalmology and Strabismus. 2012;16(5):428-430

13. Dickmann A, Petroni S, Perrotta V, Parrilla R, Aliberti S, Salerni A, Savastano MC. Measurement of retinal nerve fiber layer thickness, macular thickness, and foveal volume in amblyopic eyes using spectral-domain optical coherence tomography. J AAPOS. 2012 Feb;16(1):86-8.

14. Pang Y, Goodfellow GW, Allison C, Block S, Frantz KA. A prospective study of macular thickness in amblyopic children with unilateral high myopia. Invest Ophthalmol Vis Sci. 2011 Apr 14;52(5):2444-9.

15. Arden G, Hogg C, Carter R. Uniocular recording of pattern ERG. Vision Research. 1986;26(2):281-286.

16. Plant GT, Hess RF, Thomas SJ. The pattern evoked electroretinogram in optic neuritis. A combined psychophysical and electrophysiological study. Brain. 1986 Jun;109 (Pt 3):469-90. 